\title{
Combination of Vandetanib, Radiotherapy, and Irinotecan in the LoVo Human Colorectal Cancer Xenograft Model
}

\author{
Phyllis Wachsberger, PhD \\ Thomas Jefferson University, phyllis.wachsberger@jefferson.edu \\ Randy Burd, PhD \\ Department of Nutritional Sciences, University of Arizona, Tuscon AZ \\ Anderson Ryan, PhD \\ AstraZeneca Pharmaceuticals, Alderley Park, Macclesfield, United Kingdom \\ Constantine Daskalakis, $\mathrm{PhD}$ \\ Thomas Jefferson University, Constantine.Daskalakis@jefferson.edu \\ Adam Dicker MD, PhD \\ Thomas Jefferson University, adam.dicker@iefferson.edu \\ Follow this and additional works at: https://jdc.jefferson.edu/bodinejournal \\ Part of the Oncology Commons \\ Let us know how access to this document benefits you
}

\section{Recommended Citation}

Wachsberger, PhD, Phyllis; Burd, PhD, Randy; Ryan, PhD, Anderson; Daskalakis, PhD, Constantine; and Dicker, Adam MD, PhD (2009) "Combination of Vandetanib, Radiotherapy, and Irinotecan in the LoVo Human Colorectal Cancer Xenograft Model," Bodine Journal: Vol. 2 : Iss. 1 , Article 3.

DOI: https://doi.org/10.29046/TBJ.002.1.002

Available at: https://jdc.jefferson.edu/bodinejournal/vol2/iss1/3

This Article is brought to you for free and open access by the Jefferson Digital Commons. The Jefferson Digital Commons is a service of Thomas Jefferson University's Center for Teaching and Learning (CTL). The Commons is a showcase for Jefferson books and journals, peer-reviewed scholarly publications, unique historical collections from the University archives, and teaching tools. The Jefferson Digital Commons allows researchers and interested readers anywhere in the world to learn about and keep up to date with Jefferson scholarship. This article has been accepted for inclusion in Bodine Journal by an authorized administrator of the Jefferson Digital Commons. For more information, please contact: JeffersonDigitalCommons@jefferson.edu. 


\section{Combination of Vandetanib, Radiotherapy, and Irinotecan in the LoVo Human Colorectal Cancer Xenograft Model}

\author{
Phyllis Wachsberger, $\mathrm{PhD},{ }^{\star}$ Randy Burd, $\mathrm{PhD},{ }^{\dagger}$ Anderson Ryan, $\mathrm{PhD},{ }^{\ddagger}$ \\ Constantine Daskalakis, PhD, $\$$ and Adam P. Dicker, MD, PhD*
}

From the Departments of *Radiation Oncology and \$Pharmacology and Experimental Therapeutics, Thomas Jefferson University, Philadelphia, PA; 'Department of Nutritional Sciences, University of Arizona, Tucson, AZ; ${ }^{\ddagger}$ AstraZeneca Pharmaceuticals, Alderley Park, Macclesfield, United Kingdom

Reprinted from International Journal of Radiation Oncology Biology*Physics, Volume 75, Edition 3, Wachsberger P, Burd R, Ryan A, Daskalakis C, Dicker AP: "Combination of Vandetanib, Radiotherapy, and Irinotecan in the LoVo Human Colorectal Cancer Xenograft Model", pages 843-853, November 1, 2009. Reprinted with Permission of Elseiver.

Purpose: The tumor growth kinetics of the human LoVo colorectal xenograft model was assessed in response to vandetanib, an orally available receptor tyrosine kinase inhibitor, radiotherapy (RT), or irinotecan (CPT-11), as single therapies and in combination.

Methods and Materials: LoVo cells were injected subcutaneously into the right hind limb $\left(5 \times 10^{6}\right.$ cells in $100 \mu \mathrm{L}$ phosphate-buffered saline) of athymic NCR NUM mice and tumors were grown to a volume of $200-300 \mathrm{~mm}^{3}$ before treatment. Vandetanib was administered at $50 \mathrm{mg} / \mathrm{kg}$ daily orally for 14 days starting on Day 1 . RT was given as three fractions (3x3 Gy) on Days 1, 2 , and 3. CPT-11 was given at $15 \mathrm{mg} / \mathrm{kg}$ intraperitoneally on Days 1 and 3. Tumor volumes were measured on a daily basis and calculated by measuring tumor diameters with digital calipers in two orthogonal dimensions.

Results: All three single treatments (vandetanib, CPT-11, and radiation) significantly slowed LoVo colorectal tumor growth. Vandetanib significantly increased the antitumor effects of CPT-11 and radiation when given in combination with either of these treatments. These treatment combinations resulted in a slow tumor growth rate during the 2 weeks of vandetanib administration. The triple combination of vandetanib, CPT-11, and radiation produced the most marked improvement in response as observed by measurable shrinkage of tumors during the first week of treatment.

Conclusions: The tumor growth delay kinetics observed in this study of the LoVo colorectal model suggest concurrent and sustained post-sequencing of vandetanib with cytotoxic therapy may be beneficial in tumors of this type. (2009 Elsevier Inc.

Key Words: Vandetanib, Radiotherapy, CPT-11, LoVo colorectal cancer, Angiogenesis inhibitor.

\section{Introduction}

Colorectal cancer (CRC) remains one of the leading causes of mortality worldwide. In recent years, the most widely used chemotherapy for metastatic CRC, fluoropyrimidine (5-fluorouracil [5-FU]) in combination with folinic acid, has been combined with newer, highly active cytotoxic agents. Among these agents is the DNA topoisomerase I inhibitor, irinotecan (CPT-11), ${ }^{1}$ a potent DNA-targeting drug used in patients with CRC that is refractory to treatment with fluorouracil and leucovorin. This cytotoxic agent is, in turn, being combined with new molecular therapies targeting the tumor vasculature and key signaling pathways controlling tumor cell proliferation, angiogenesis, and survival in CRC. In this regard, the epidermal growth factor receptor (EGFR) plays an important role in CRC tumor growth and progression, ${ }^{2}$ and cetuximab, a monoclonal antibody specific for EGFR, has been approved for use in combination with CPT-11 in patients with EGFR-expressing CRC refractory to CPT-11-based chemotherapy. ${ }^{3}$ In addition, bevacizumab, a monoclonal antibody specific for vascular endothelial growth factor (VEGF-A), a key player in tumor angiogenesis in CRC as well as other solid tumors, has been approved for the treatment of metastatic CRC in combination with intravenous 5-FU-based chemotherapies. ${ }^{4}$ Despite recent improvements in treatment for CRC, a need still remains to improve the performance of existing treatments and to establish the optimum scheduling and dosing of combined therapies.

Vandetanib (ZACTIMA) is an oral receptor tyrosine kinase inhibitor that, in recombinant enzyme assays, demonstrates potent activity against vascular endothelial growth factor receptor-2 (VEGFR-2) tyrosine kinase (the half maximal inhibitory concentration $\left[\mathrm{IC}_{50}\right]=40$ $\mathrm{nmol} / \mathrm{L}$ ) with additional activity against EGFR $\left(\mathrm{IC}_{50}=500 \mathrm{nmol} / \mathrm{L}\right)$ and the rearranged during transfection (RET) tyrosine kinases $\left(\mathrm{IC}_{50}=130 \mathrm{nM}\right)$ tyrosine kinases. ${ }^{5-8}$ Vandetanib has orphan-drug status in the United States and Europe for medullary thyroid cancer (in which RET activity is important) and is in Phase III development in non-small-cell lung cancer and medullary thyroid cancer. Phase II studies are ongoing to investigate its efficacy in other tumor types, thyroid cancer, hepatocellular carcinoma, and glioblastoma.

Vandetanib has been shown to enhance the efficacy of radiotherapy in subcutaneous and orthotopic tumor xenograft models. ${ }^{9-13}$ The combination of vandetanib, radiation, and current chemotherapeutic agents used in CRC treatment has not been studied. Preclinical demonstration of efficacy of a combination protocol with novel agents plus radiation is usually considered crucial before clinical evaluation. The purpose of the present study was to examine the effect of vandetanib on the radiation response of a colorectal tumor model when administered in combination with CPT-11. It was hypothesized that simultaneous inhibition of VEGFR and EGFR by vandetanib in combination with the cytotoxic agent CPT-11 would interact to enhance radiation response and tumor control 
in the human LoVo colorectal tumor cell model. The LoVo colorectal model expresses activated EGFR ${ }^{14,15}$ and is highly vascularized and therefore is an appropriate model to test the hypothesis.

\section{Methods and Materials}

\section{Animal and tumor model}

LoVo cell suspensions ( $5 \times 10^{6}$ cells in $100 \mu \mathrm{L}$ phosphate buffered saline) were implanted subcutaneously into the right hind limbs of 6- to 8week-old athymic NCR NUM mice (Taconic Farms, Hudson, NY). A subcutaneous xenograft model was chosen to facilitate radiation dosing and ease of tumor measurements. Tumors were allowed to grow for approximately 25 days, until reaching an approximate volume of 200$300 \mathrm{~mm}^{3}$ at the start of treatment (Day 1). All animals were randomized among treatment groups.

\section{Drug treatment}

Vandetanib (AstraZeneca, Macclesfield, UK) was administered by oral gavage at $50 \mathrm{mg} / \mathrm{kg}$ daily for 14 days, starting on Day 1 . Vandetanib dosing in this study was based on previous pharmacokinetic studies in mouse models predicting relevance of this dosing to clinical drug exposure in human patients. ${ }^{16} \mathrm{CPT}-11$ was given at $15 \mathrm{mg} / \mathrm{kg}$ intraperitoneally on Days 1 and 3.

\section{Radiation treatment}

Irradiation was performed on anesthetized mice using $\mathrm{X}$-rays generated by a PanTak, $310 \mathrm{kVe} \mathrm{X}$-ray machine, $0.25 \mathrm{~mm} \mathrm{Cu}+1 \mathrm{~mm} \mathrm{Al}$ added filtration, at $125 \mathrm{cGy} / \mathrm{min}$. Dosimetry was performed by an in-the-beam ionization chamber calibrated against a primary standard. Corrections were made daily for humidity, temperature, and barometric pressure. Mice were anesthetized with a combination of ketamine and acepromazine

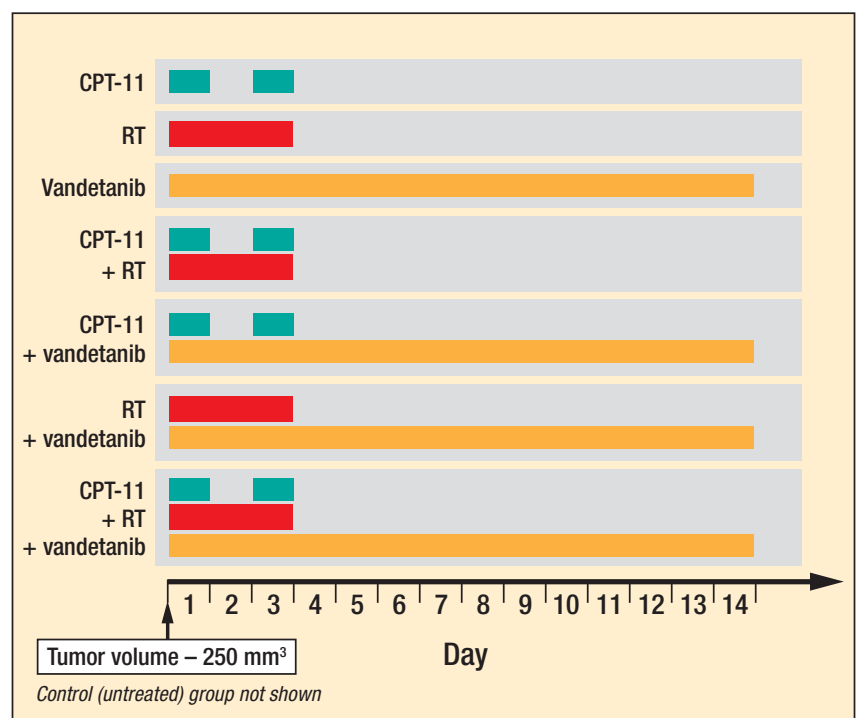

Figure 1. Summary of treatment groups. LoVo cells were implanted subcutaneously into the right hind limbs of athymic NCR NUM male mice. Mice were randomized into eight experimental groups (11-16 animals per group). Vandetanib was administered at $50 \mathrm{mg} /$ $\mathrm{kg}$ daily orally for 14 days, starting on Day 1 . CPT-11 was given at $15 \mathrm{mg} / \mathrm{kg}$ intraperitoneally on Days 1 and 3. Radiation was given as three fractions ( $3 \times 3 \mathrm{~Gy}$ ) on Days 1, 2, and 3. at a concentration of $37.5 \mathrm{mg} / \mathrm{kg}$ and $0.2 \mathrm{mg} / \mathrm{kg}$, respectively, to provide 25-30 min of sedation. Each mouse was confined in a lead casing with its tumor-bearing leg extended through an opening on the side to allow the tumor to be irradiated locally. Radiation was administered as three daily fractions of 3 Gy each on Days 1, 2, and 3. On days when radiation was administered with vandetanib or CPT-1, vandetanib and CPT-11 were given approximately $2 \mathrm{~h}$ before radiation, with vandetanib preceding CPT-11 administration.

\section{Tumor measurement}

Tumors were synchronized to be approximately $250 \mathrm{~mm}^{3}$ at the start of treatment (Day 1) and were measured four to five times per week, for up to 6 weeks of follow-up, or until they reached 2,000 $\mathrm{mm}^{3}$. Tumor size was determined by direct measurement with calipers and calculated by the formula: (smallest diameter ${ }^{2} \mathrm{x}$ widest diameter)/2. Tumors were not allowed to grow beyond 2,000 $\mathrm{mm}^{3}$ in accordance with Institutional Animal Care and Use Committee regulations.

\section{In vivo tumor necrosis}

Tumors were collected from animals on Day 14 after the start of treatment for fixation and staining with hematoxylin and eosin. The area of necrosis was evaluated by image analysis and expressed as the percentage of the total tumor area.

\section{Statistical analysis}

Tumor growth was analyzed via mixed-effects regression, as previously described. The method was used because it does not depend on an arbitrary end point target tumor size, but uses the repeated tumor size measurements obtained over the entire study period, while appropriately handling unbalanced data (i.e., different number of measurements for different animals) and the correlation of each animal's measurements over time. Mixed-effects regression yields generalizable parameters of interest (e.g., average daily tumor growth rate, tumor doubling time), and can investigate treatment interactions and nonlinear patterns of tumor growth. The base-10 logarithm of tumor volume was modeled as a function of time and treatment. Linear or quadratic growth curves over time were fitted to the log-transformed data, depending on growth patterns in each treatment group. All statistical analyses were conducted in SAS 9.2 (SAS Institute Inc., Cary, NC, 1999-2001).

\section{Results}

The experiment involved three different treatments (vandetanib, CPT-11, and radiotherapy), as described above and summarized in Fig. 1. Data were collected from a total of 104 animals in eight experimental groups (11-16 animals per group) and are summarized in Fig. 2. Starting tumor sizes were comparable across groups, with geometric means ranging from 230 to $257 \mathrm{~mm}^{3}$ ( $p=0.771$ ). All treatments were well tolerated in the animals with no observable loss of body weight.

The three single-treatment groups (CPT-11, radiation, or vandetanib), as well as the combination of CPT-11 with radiation (Fig. 2) were fitted to log-transformed curves, whereas the three remaining groups that received combination treatments involving vandetanib showed a significantly nonlinear tumor growth and were fitted to quadratic curves.

Figure 3 shows the measured geometric mean tumor size graphically over time. Table 1 shows the corresponding calculated tumor growth parameters (daily tumor growth rate and tumor doubling time). Table 2 shows $p$ values for group comparisons at 7, 14, and 21 days after start of treatment. 

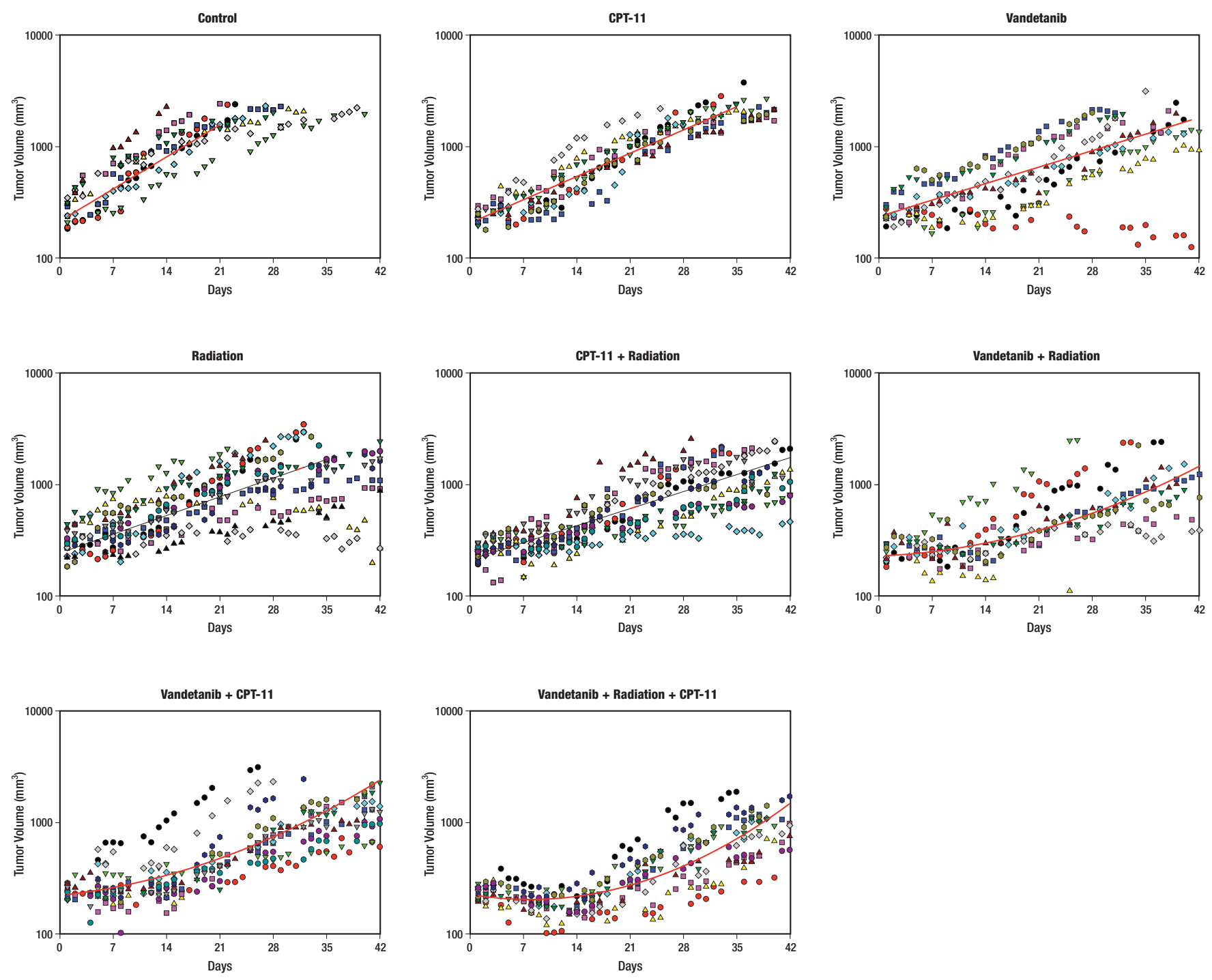

Figure 2. Tumor growth curves in LoVo xenografts treated with vandetanib, irinotecan (CPT-11), and/or radiation. Individual mouse data are shown for eight treatment groups (11-16 animals per group), along with fitted group curves. Vandetanib was administered at $50 \mathrm{mg} / \mathrm{kg}$ daily orally for 14 days, starting on Day 1 . CPT-11 was given at $15 \mathrm{mg} / \mathrm{kg}$ intraperitoneally on Days 1 and 3. Radiation was given as three fractions (3x3 Gy) on Days 1, 2, and 3 .

The control group had an estimated average daily tumor growth rate of $9.9 \%$, corresponding to an average tumor doubling time of about 7 days (Table 1). All three single treatments resulted in a significant inhibition of tumor growth, compared with the control group (average daily tumor growth rates: CPT-11: $7.1 \%, p=0.015$; radiation: $5.6 \%$, $p=0.001$; vandetanib: $5.0 \%, p=0.001)$. Vandetanib inhibited tumor growth significantly more than CPT-11 $(p=0.043)$, but not radiation $(p=0.514)$; radiation and CPT-11 were not significantly different $(p=0.139)$. The combination of CPT-11 with radiation produced a daily tumor growth rate of $5.1 \%$, which was significantly lower than CPT-11 alone ( $p=0.015)$ but comparable to radiation alone $(p=0.560)$. There was no significant (additive) interaction between CPT-11 and radiation $(p=0.105)$.
The remaining three groups that received treatment combinations involving vandetanib (with either CPT-11 or radiation, or with both CPT-11 and radiation), showed significant treatment interactions ( $p=0.001$ for the interaction between vandetanib and CPT-11 and between vandetanib and radiation) and nonlinear tumor growth patterns. Compared with single-treatment groups, growth was significantly delayed (and, in the triple-treatment combination, tumor volume actually decreased) early on, but progressively accelerated later, although it never exceeded that of the untreated controls (Fig. 3). Because of the nonlinearity of tumor growth in these groups, tumor growth parameters are not constant over time and comparisons depend on the time point referenced. Table 2 shows $p$ values for Days 7, 14, and 21 . 


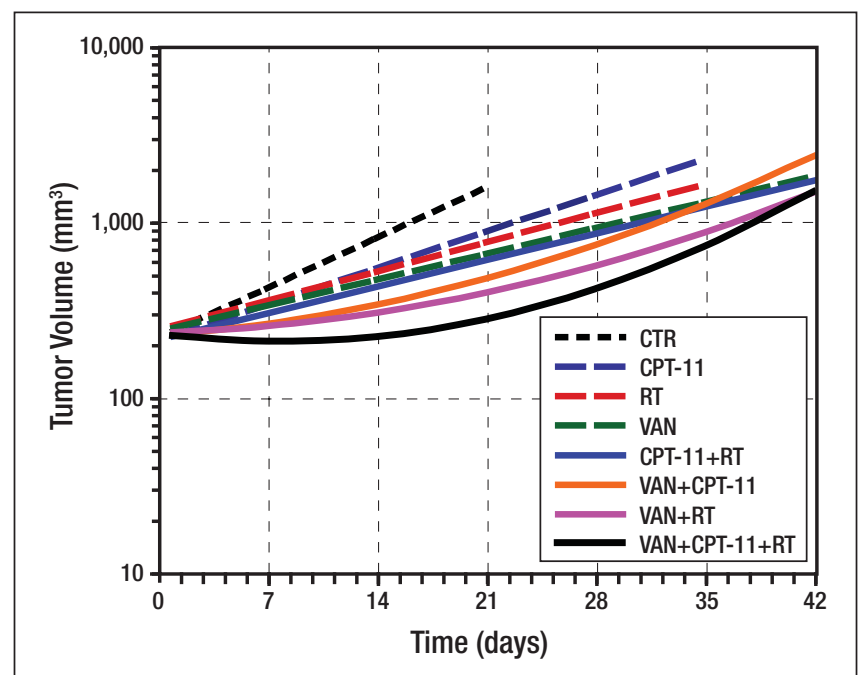

Figure 3. Estimated geometric mean tumor volume over time in LoVo xenografts treated with vandetanib, CPT-11, and/or radiation. Vandetanib was administered at $50 \mathrm{mg} / \mathrm{kg}$ daily orally for 14 days, starting on Day 1. CPT-11 was given at $15 \mathrm{mg} / \mathrm{kg}$ intraperitoneally on Days 1 and 3. Radiation was given as three fractions (3x3 Gy) on Days 1, 2, and 3.

During the first week of treatment, animals receiving the combination of vandetanib with CPT-11 had average daily tumor growth rate of less than $3.5 \%$, significantly lower than CPT-11 alone and marginally so compared with vandetanib alone $(p=0.001$ and 0.058 , respectively, after 7 days). By the end of the 2 -week vandetanib treatment, the tumor growth rate in the combination group $(4.6 \%)$ was still significantly lower than for CPT-11 alone $(p=0.015)$ but comparable to that for vandetanib alone $(p=0.682)$. By the third and fourth weeks, tumor growth had reached levels similar to those seen in the single-treatment groups (Fig. 3, Table 1).

The combination of vandetanib with radiation resulted in a similar pattern of nonlinear tumor growth inhibition. After the first 7 days, the average daily tumor growth rate of $2.1 \%$ was significantly lower than for either radiation alone or vandetanib alone $(p=0.005$ and 0.019 , respectively). After 14 days, the tumor growth rate in the combination group had accelerated to $3.4 \%$ and was only marginally lower than for radiation alone and comparable to that for vandetanib alone ( $p=0.080$ and 0.212 , respectively). By the third and fourth weeks, tumor growth had become similar to that seen in the singletreatment groups (Fig. 3, Table 1).

Despite delaying tumor growth in the initial weeks, the treatment combinations induced only modest levels of tumor necrosis (10-20\%), with no significant differences between treatment groups (Fig. 4).

The pattern of tumor growth in the group that received the tripletreatment combination reflected both the interaction between vandetanib and CPT-11 and that between vandetanib and radiation (as mentioned previously). Thus, during the first week, instead of the delayed tumor growth seen in the two-treatment combinations, tumor volume in the triple-treatment combination actually decreased ( $p=0.001$ vs. vandetanib plus CPT-11, and 0.052 vs. vandetanib plus radiation). After that time, similar to the two-treatment combinations that involved vandetanib, tumor growth started accelerating. By the end of the third week, tumor growth in the triple-treatment combination group was similar to that in the two-treatment combination groups involving vandetanib, and by the fourth week, it was similar to that in the single-treatment groups.

\section{Discussion}

Relatively little is known about the antitumor effects of combining cytotoxic drugs, radiotherapy, and novel targeted therapies that specifically interfere with signaling pathways controlling cancer proliferation, angiogenesis, and survival. In the present study, vandetanib, a potent inhibitor of both VEGFR and EGFR signaling, was combined with CPT-11 or radiation, to determine if greater anti-colorectal tumor activity can be obtained.

This study demonstrated that all three single treatments (vandetanib, CPT-11, and radiation) significantly slowed LoVo colorectal tumor growth. Previous studies with single-agent vandetanib demonstrated that chronic oral administration reduced tumor vascularity and tumor growth in a variety of xenograft models, including CRC. ${ }^{7,17}$ In the clinic, the safety and tolerability of vandetanib has been demonstrated in patients with advanced colorectal cancer as well as other solid tumors. ${ }^{18}$

Table 1. Estimates of the average daily tumor growth rate and average tumor doubling time, by treatment group

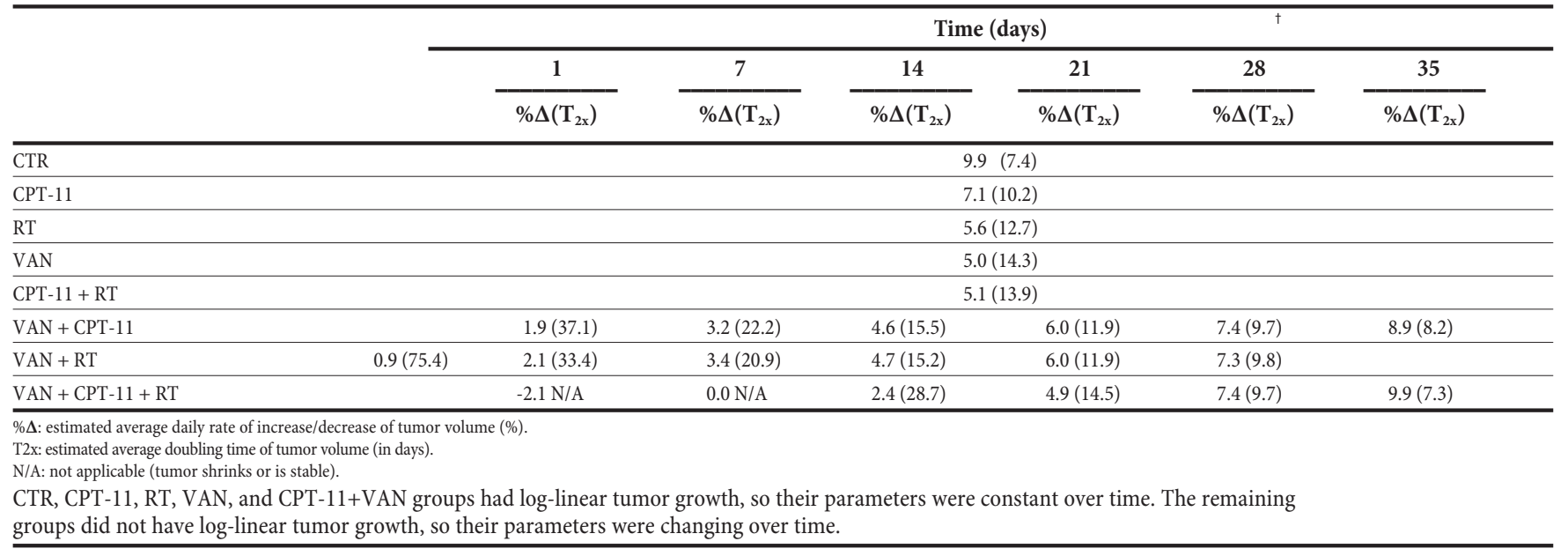


Table 2. P-values for comparisons of treatment groups, on days 7,14 , and 21 , after the start of treatment

\begin{tabular}{|c|c|c|c|}
\hline & Day 7 & Day 14 & Day 21 \\
\hline \multicolumn{4}{|l|}{ CTR } \\
\hline CPT-11 & & 0.015 vs. CTR; 0.139 vs. RT; 0.043 vs. VAN & \\
\hline RT & & 0.001 vs. CTR; 0.139 vs. CPT- $11 ; 0.514$ vs. VAN & \\
\hline VAN & & 0.001 vs. CTR; 0.043 vs. CPT- $11 ; 0.514$ vs. RT & \\
\hline $\mathrm{CPT}-11+\mathrm{RT}$ & & 0.001 vs. CPT- $11 ; 0.560$ vs. RT & \\
\hline $\mathrm{VAN}+\mathrm{CPT}-11$ & 0.001 vs. CPT- $11 ; 0.058$ vs. VAN & 0.015 vs. CPT- $11 ; 0.682$ vs. VAN & 0.346 vs. CPT- $11 ; 0.395$ vs. VAN \\
\hline $\mathrm{VAN}+\mathrm{RT}$ & 0.005 vs. RT; 0.019 vs. VAN & 0.080 vs. RT; 0.212 vs. VAN & 0.496 vs. RT; 0.830 vs. VAN \\
\hline $\mathrm{VAN}+\mathrm{CPT}-11+\mathrm{RT}$ & $\begin{array}{l}0.001 \text { vs. CPT- } 11 ; 0.001 \text { vs. RT; } \\
0.001 \text { vs. VAN } \\
0.001 \text { vs. CPT- } 11+\text { RT; } 0.001 \text { vs. } \\
\text { VAN+CPT- } 11 ; 0.052 \text { vs. } \\
\text { VAN+RT }\end{array}$ & $\begin{array}{l}0.001 \text { vs. CPT- } 11 ; 0.001 \text { vs. RT; } \\
0.007 \text { vs. VAN } \\
0.001 \text { vs. CPT- } 11+\text { RT; } 0.017 \text { vs. } \\
\text { VAN+CPT- } 11 ; 0.407 \text { vs. } \\
\text { VAN+RT }\end{array}$ & $\begin{array}{l}0.011 \text { vs. CPT- } 11 ; 0.366 \text { vs. RT; } \\
0.917 \text { vs. VAN } \\
0.766 \text { vs. CPT- } 11+\text { RT; } 0.294 \text { vs. } \\
\text { VAN+CPT- } 11 ; 0.868 \text { vs. } \\
\text { VAN+RT }\end{array}$ \\
\hline
\end{tabular}

CTR, CPT-11, RT, VAN, and CPT-11+VAN groups had log-linear tumor growth and therefore comparisons do not depend on time.

The remaining groups did not have log-linear tumor growth and therefore comparisons that involve them depend on time.

Vandetanib induced manageable normal tissue toxicities related to inhibition of EGFR and VEGFR signaling such as diarrhea, rash, and hypertension. ${ }^{19,20}$ The effect of combining radiation and vandetanib on normal tissue is currently unknown, however it has been shown in both preclinical and clinical trials that use of VEGF inhibitors with radiation may result in higher rates of normal tissue toxicity such as induction of thrombosis, hemorrhage, and bowel toxicities. ${ }^{21-23}$ In contrast, it was postulated that combination of radiotherapy with inhibitors of angiogenesis may actually decrease these risks because radiotherapy has been used to prevent hemorrhage. ${ }^{24}$ Overall, the investigation of agents such as vandetanib in combination with radiation in normal tissue is lacking, and thus will be a major focus in the future.

As previously discussed, single-agent vandetanib has dual tyrosine kinase inhibitory activity against VEGFR-2 and EGFR, which allows it to target two key pathways responsible for tumor growth (i.e., tumor angiogenic signaling, tumor cell proliferation). It has been speculated that dual suppression may be critical for sustained suppression of tumor growth, especially because the EGFR and VEGFR pathways are linked and exhibit cross-talk. ${ }^{25}$ In addition, vandetanib can also enhance the antiproliferative activity of selective EGFR inhibitors such as cetuximab, thereby potentiating suppression of EGFR signaling. ${ }^{17}$

The present study confirmed that vandetanib, chronically administered over 2 weeks, slowed tumor growth in a colorectal tumor model, and, under the dosing conditions of this study, slowed tumor growth to a greater extent than CPT-11 alone and to a similar level to radiation alone. Moreover, vandetanib significantly increased the antitumor effects of CPT-11 and radiation, when given in combination with either of these treatments. In particular, these treatment combinations resulted in a slow tumor growth rate during the 2 weeks of vandetanib administration. These results confirm an earlier study by Troiani et al. ${ }^{26}$ in which vandetanib
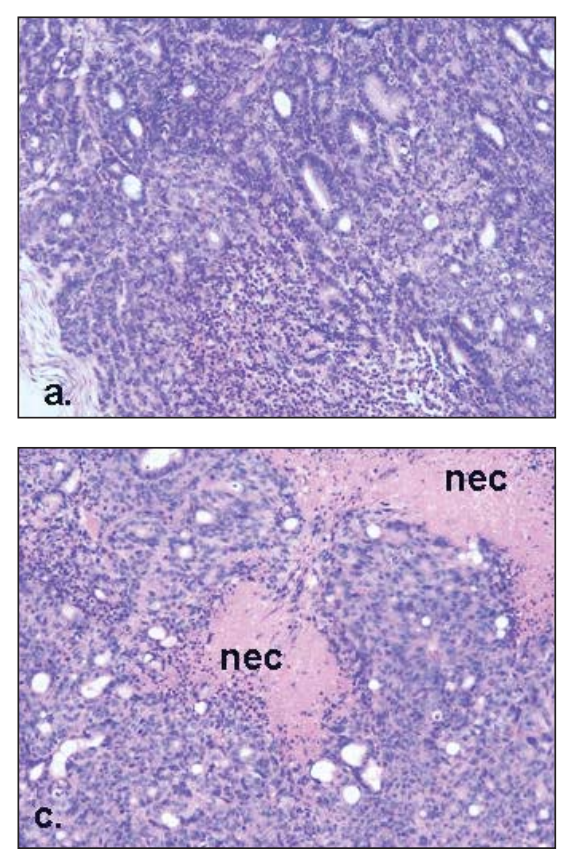
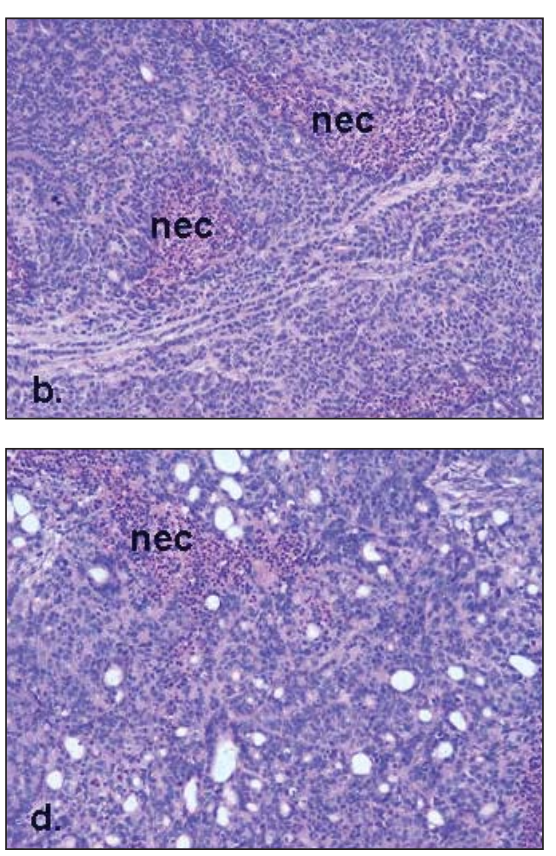

Figure 4. Hematoxylin and eosin stained sections of LoVo colorectal xenografts. All tumors were collected from animals on Day 14 after the start of treatment. Areas of necrosis are denoted by nec. Magnification 20x. (a) Control (untreated) tumor, showing $2 \%$ necrosis. (b) Tumor from animal after administration of last dose of vandetanib, showing 15\% necrosis. (c) Tumor from animal after administration of CPT-11 and RT, showing $20 \%$ necrosis. (d) Tumor from animal after administration of vandetanib and CPT-11, showing $10 \%$ necrosis. 
$(25 \mathrm{mg} / \mathrm{kg} /$ day) administered in combination with CPT-11 exhibited high antitumor activity in HT29-tumor-bearing nude mice. Troiani et al. showed a correlation between this dosing schedule and enhanced EGFR and VEGFR signal inhibition.

In the present study, the triple combination of vandetanib, CPT-11, and radiation produced the most marked improvement in response in the LoVo- tumor-bearing mice. The triple treatment produced a measurable shrinkage of tumors during the first week of treatment. The combination of vandetanib, chemotherapy (gemcitabine), and radiation has also been previously shown to significantly inhibit tumor progression in a pancreatic tumor model. ${ }^{27}$ Importantly, the present study also investigated the kinetics of tumor growth, both during and after a course of treatment. It was demonstrated that the addition of vandetanib significantly enhanced the initial antitumor effect of chemo-radiation. However, when vandetanib treatment ended, tumor growth returned to near control (untreated) levels. Therefore, these data support the rationale of adding an antivascular agent to cytotoxic therapies and provide valuable information for the design of therapeutic protocols.

The precise mechanisms leading to initial tumor regression with the combined therapies in this study are not known. Analysis of interactions between cytotoxic agents and vandetanib is complex, given that both the tumor cells and the tumor microenvironment are affected. In this connection, radiation can kill not only tumor cells but also endothelial cells of the tumor vasculature, thereby affecting the radiosensitivity of the tumor $(28,29)$. In addition, cytotoxic agents have mechanisms of cell killing that are different from the targeted agent. Both radiation and CPT-11 kill cells through DNA damage. Both chemotherapy and radiation can also alter cellular signaling pathways by inducing EGFR phosphorylation and through the growth factor signaling pathway, contribute to tumor cell proliferation and survival. ${ }^{30-32}$ Preclinical studies have also shown that cytotoxic therapy alone, such as radiation, can result in intensification of angiogenic processes. ${ }^{33}$ After cytotoxic treatment, upregulation of vascular growth factors and their receptors occurs, which contributes to tumor recurrence and progression. ${ }^{34}$ Direct upregulation of VEGF after irradiation of various cancer cell lines has been reported. ${ }^{35}$ Radiation also induces transient tumor hypoxia which results in upregulation of hypoxia inducible factor-1 (HIF-1) which can stimulate VEGF and VEGFR-2 expression. Therefore, simultaneous inhibition of both VEGFR and EGFR signaling through chronic administration of vandetanib in combination with cytotoxic therapy is expected to suppress the upsurge in pro-proliferative and angiogenic signaling resulting from CPT-11 and radiation-induced EGFR and VEGF. This suppression will thereby lead to inhibition of vascular protective mechanisms and growth factor mechanisms contributing to tumor regrowth.

The increased tumor growth that was seen in this study after discontinuation of vandetanib suggests that inhibition of angiogenic and proproliferative signaling is readily reversed. The current observations are in agreement with a number of both preclinical and clinical studies showing that tumors can adapt to anti-angiogenic treatment by undergoing "evasive resistance" to angiogenesis inhibitors. ${ }^{36}$ Mechanisms of resistance include upregulation of alternative proangiogenic signaling pathways as well as recruitment of bone marrow-derived proangiogenic cells. ${ }^{37,} 38$ In addition, administration of vandetanib itself has been observed to increase VEGF production in certain cancer cell lines as well as in tumor xenografts, ${ }^{39,} 40$ thereby suggesting an additional contributing mechanism to tumor relapse. More studies will be needed to determine whether additional angiogenic pathways may be induced by triple modality treatment.

\section{Conclusions}

The results of this study provide a scientific rationale for testing the combination of vandetanib, CPT-11, and radiation in patients with CRC. Although the best schedule and sequencing for this triple modality treatment has yet to be determined, the tumor growth delay kinetics observed in this study suggest that improvement in colorectal tumor response can be obtained by concurrent and sustained postsequencing of vandetanib with cytotoxic therapy, keeping in mind that prolonged chronic administration of the receptor tyrosine kinase inhibitors may lead to the development of resistance and the requirement for additional therapeutic agents as seen with other targeted agents, such as imatinib and gefitinib. ${ }^{41,42}$

\section{References}

1. Tewes M, Schleucher N, Achterrath W, et al. Capecitabine and irinotecan as first-line chemotherapy in patients with metastatic colorectal cancer: Results of an extended phase I study. Ann Oncol 2003;14:1442-1448

2. Roberts RB, Min L, Washington MK, et al. Importance of epidermal growth factor recepto signaling in establishment of adenomas and maintenance of carcinomas during intestinal tumorigenesis. Proc Natl Acad Sci U S A 2002;99:1521-1526.

3. Cunningham D, Humblet $Y$, Siena $S$, et al. Cetuximab monotherapy and cetuximab plus irinotecan in irinotecan-refractory metastatic colorectal cancer. N Engl J Med 2004;351:337-345

4. Hurwitz H, Fehrenbacher L, Novotny W, et al. Bevacizumab plus irinotecan, fluorouracil, and leucovorin for metastatic colorectal cancer. N Engl J Med 2004;350:2335-2342.

5. Carlomagno F, Vitagliano D, Guida T, et al. ZD6474, an orally available inhibitor of KDR tyrosine kinase activity, efficiently blocks oncogenic RET kinases. Cancer Res 2002;62:7284-7290.

6. Ciardiello F, Caputo R, Damiano V, et al. Antitumor effects of ZD6474, a small molecule vascular endothelial growth factor receptor tyrosine kinase inhibitor, with additional activity against epidermal growth factor receptor tyrosine kinase. Clin Cancer Res 2003;9:1546-1556.

7. Ryan AJ, Wedge SR. ZD6474 - a novel inhibitor of VEGFR and EGFR tyrosine kinase activity. Br J Cancer 2005;92(Suppl1):S6-S13.

8. Wedge SR, Ogilvie DJ, Dukes M, et al. ZD6474 inhibits vascular endothelial growth factor signaling, angiogenesis, and tumor growth following oral administration. Cancer Res 2002;62:4645-4655.

9. Brazelle WD, Shi W, Siemann DW. VEGF-associated tyrosine kinase inhibition increases the tumor response to single and fractionated dose radiotherapy. Int J Radiat Oncol Biol Phys 2006;65:836-841.

10. Damiano V, Melisi D, Bianco C, et al. Cooperative antitumor effect of multitargeted kinase inhibitor ZD6474 and ionizing radiation in glioblastoma. Clin Cancer Res 2005;11:5639-5644.

11. Frederick B, Gustafson D, Bianco C, et al. ZD6474, an inhibitor of VEGFR and EGFR tyrosine kinase activity in combination with radiotherapy. Int J Radiat Oncol Biol Phys 2006;64:33-37.

12. Sandstrom M, Johansson M, Bergstrom P, et al. Effects of the VEGFR inhibitor ZD6474 in combination with radiotherapy and temozolomide in an orthotopic glioma model. J Neurooncol 2008;88:1-9.

13. Williams KJ, Telfer BA, Brave S, et al. ZD6474, a potent inhibitor of vascular endothelial growth factor signaling, combined with radiotherapy: Schedule-dependent enhancement of antitumo activity. Clin Cancer Res 2004;10:8587-8593.

14. Koizumi F, Kanzawa F, Ueda Y, et al. Synergistic interaction between the EGFR tyrosine kinase inhibitor gefitinib ("Iressa") and the DNA topoisomerase I inhibitor CPT-11 (irinotecan) in human colorectal cancer cells. Int J Cancer 2004;108:464-472.

15. Nyati MK, Maheshwari D, Hanasoge S, et al. Radiosensitization by pan ErbB inhibitor CI-1033 in vitro and in vivo. Clin Cancer Res 2004;10:691-700.

16. Gustafson DL, Bradshaw-Pierce EL, Merz AL, et al. Tissue distribution and metabolism of the tyrosine kinase inhibitor ZD6474 (Zactima) in tumor-bearing nude mice following oral dosing. J Pharmacol Exp Ther 2006;318:872-880.

17. Morelli MP, Cascone T, Troiani T, et al. Anti-tumor activity of the combination of cetuximab, an anti-EGFR blocking monoclonal antibody and ZD6474, an inhibitor of VEGFR and EGFR tyrosine kinases. J Cell Physiol 2006;208:344-353.

18. Morabito A, Piccirillo MC, Falasconi F, et al. Vandetanib (ZD6474), a dual inhibitor of vascular endothelial growth factor receptor (VEGFR) and epidermal growth factor receptor (EGFR) tyrosine kinases: Current status and future directions. Oncologist 2009;14:378-390.

19. Michael M, Gibbs P, Smith R, et al. Open-label phase I trial of vandetanib in combination with mFOLFOX6 in patients with advanced colorectal cancer. Invest New Drugs 2009;27:253-261.

20. Natale RB, Bodkin D, Govindan R, et al. Vandetanib versus gefitinib in patients with advanced non-small-cell lung cancer: Results from a two-part, double-blind, randomized Phase II Study. J Clin Oncol 2009;27:2523-2529.

21. Johnson DH, Fehrenbacher L, Novotny WF, et al. Randomized phase II trial comparing bevacizumab plus carboplatin and paclitaxel with carboplatin and paclitaxel alone in previously untreated locally advanced or metastatic non-small-cell lung cancer. J Clin Oncol 2004;22:2184-2191. 
22. Levine RJ, Maynard SE, Qian C, et al. Circulating angiogenic factors and the risk of preeclampsia. N Engl J Med 2004;350:672-683.

23. Senan S, Smit EF. Design of clinical trials of radiation combined with antiangiogenic therapy. Oncologist 2007;12:465-477.

24. Shibuya K, Komaki R, Shintani T, et al. Targeted therapy against VEGFR and EGFR with ZD6474 enhances the therapeutic efficacy of irradiation in an orthotopic model of human nonsmall-cell lung cancer. Int J Radiat Oncol Biol Phys 2007;69:1534-1543.

25. Pennell NA, Lynch TJ Jr. Combined inhibition of the VEGFR and EGFR signaling pathways in the treatment of NSCLC. Oncologist 2009;14:399-411.

26. Troiani T, Serkova NJ, Gustafson DL, et al. Investigation of two dosing schedules of vandetanib (ZD6474), an inhibitor of vascular endothelial growth factor receptor and epidermal growth factor receptor signaling, in combination with irinotecan in a human colon cancer xenograft model. Clin Cancer Res 2007;13:6450-6458.

27. Bianco C, Giovannetti E, Ciardiello F, et al. Synergistic antitumor activity of ZD6474, an inhibitor of vascular endothelial growth factor receptor and epidermal growth factor receptor signaling, with gemcitabine and ionizing radiation against pancreatic cancer. Clin Cancer Res 2006;12:7099-7107

28. Garcia-Barros M, Paris F, Cordon-Cardo C, et al. Tumor response to radiotherapy regulated by endothelial cell apoptosis. Science 2003;300:1155-1159.

29. Paris F, Fuks Z, Kang A, et al. Endothelial apoptosis as the primary lesion initiating intestinal radiation damage in mice. Science 2001;293:293-297.

30. Balaban N, Moni J, Shannon M, et al. The effect of ionizing radiation on signal transduction: Antibodies to EGF receptor sensitize A431 cells to radiation. Biochim Biophys Acta 1996;1314:147-156.

31. Schmidt-Ullrich RK, Mikkelsen RB, Dent P, et al. Radiation-induced proliferation of the human A431 squamous carcinoma cells is dependent on EGFR tyrosine phosphorylation. Oncogene 1997;15:1191-1197.

32. Van SS, Kyula J, Kelly DM, et al. Chemotherapy-induced epidermal growth factor receptor activation determines response to combined gefitinib/chemotherapy treatment in non-small cell lung cancer cells. Mol Cancer Ther 2006;5:1154-1165.

33. Koukourakis MI, Giatromanolaki A, Sivridis E, et al. Squamous cell head and neck cancer: Evidence of angiogenic regeneration during radiotherapy. Anticancer Res 2001;21:4301-4309.

34. Taylor AP, Osorio L, Craig R, et al. Tumor-specific regulation of angiogenic growth factors and their receptors during recovery from cytotoxic therapy. Clin Cancer Res 2002;8:1213-1222.

35. Gorski DH, Beckett MA, Jaskowiak NT, et al. Blockage of the vascular endothelial growth factor stress response increases the antitumor effects of ionizing radiation. Cancer Res 1999;59:3374-3378.

36. Bergers G, Hanahan D. Modes of resistance to anti-angiogenic therapy. Nat Rev Cancer 2008;8:592-603.

37. Casanovas O, Hicklin DJ, Bergers G, et al. Drug resistance by evasion of antiangiogenic targeting of VEGF signaling in latestage pancreatic islet tumors. Cancer Cell 2005;8:299-309.

38. Du R, Lu KV, Petritsch C, et al. HIFlalpha induces the recruitment of bone marrow-derived vascular modulatory cells to regulate tumor angiogenesis and invasion. Cancer Cell 2008; $13: 206-220$

39. Sasaki T, Tanno S, Shibukawa K, et al. Administration of VEGF receptor tyrosine kinase inhibitor increases VEGF production causing angiogenesis in human small-cell lung cancer xenografts. Int J Oncol 2008;33:525-532

40. Showalter TN, Daroczi B, Halko R, et al. ZD6474 enhances radiation therapy in human glioblastoma xenografts which contain the EGFRvIII mutation or overexpress wtEGFR. Abstract, Radiation Research Society Annual Meeting 2008 (Boston, MA) Radiation Research Society Annual Meeting 2008.

41. Komarova NL, Katouli AA, Wodarz D. Combination of two but not three current targeted drugs can improve therapy of chronic myeloid leukemia. PLoS ONE 2009;4:e4423.

42. Okabe T, Okamoto I, Tsukioka S, et al. Addition of S-1 to the epidermal growth factor receptor inhibitor gefitinib overcomes gefitinib resistance in non-small cell lung cancer cell lines with MET amplification. Clin Cancer Res 2009;15:907-913. 